\title{
The role of the psychotherapist as consultant to in-patient psychiatric units*
}

\author{
Mike Hoвbs, Clinical Lecturer in Psychotherapy, University of Oxford and Consultant \\ Psychotherapist, The Warneford Hospital, Oxford OX3 7JX
}

The psychotherapist as consultant to in-patient psychiatric units may undertake any one of a number of specific tasks. Central to, and common to these, is his support of the effective work of the psychiatric unit's staff. The consultant's contribution is directed primarily towards enabling the staff to utilise themselves, i.e. their selves, to the full in their treatment of the patients.

This paper addresses the role of the psychotherapist as a consultant to in-patient psychiatric units. It does not refer specifically to consultation in residential psychotherapeutic communities, although the same fundamental principles guide the consultation process in both settings; nor does it dwell on the psychotherapeutic treatments possible in psychiatric wards, or on the psychotherapist's potential contribution to them as therapist or supervisor.

\section{Analytic stance}

Whatever the task being undertaken, the consultation process requires an analytic stance that depends on two essential qualities in the consultant: detachment and a psychodynamic perspective.

The detachment necessary for effective consultation requires that the consultant is neither too caught up in the administrative and clinical responsibilities of the unit, nor invested in it for the satisfaction of his own emotional needs. He may not be involved in face-to-face work with patients at all.

By maintaining a degree of detachment, the consultant can draw maximally on his powers of perception and observation while remaining available for the other functions which follow from this observation. Without such detachment, he cannot represent a psychodynamic viewpoint reliably and without compromise.

The psychodynamic perspective is necessary in order to make sense of what is observed in the working of the unit. It depends on a sound knowledge of the psychologies of the individual, the group and the institution - and of the interactions between them.

*Based on a lecture given to the Royal College of Psychiatrists' Quarterly Meeting, October 1988.

\section{Consultation to a psychiatric unit}

Let me enumerate some of the tasks undertaken by the psychotherapist consultant in a psychiatric unit. We are consulted by medical and non-medical colleagues who may present any one of a number of requests:

(a) to conduct, or to supervise others who conduct, in-patient psychotherapy groups as an adjunct to other forms of treatment

(b) to treat, or more often to supervise others who treat, selected in-patients in individual, family or specialised group therapy

(c) to 'advise' about the psychological aspects of management of difficult or intractable patients

(d) to assist in the planning and development of psychological treatment programmes in the psychiatric unit

(e) to chair community meetings, or in other ways to contribute to the creation and maintenance of a therapeutic 'milieu' in the ward or unit

(f) to support the psychiatric unit's staff, routinely perhaps through conducting a staff sensitivity group; but also in other ways at times of personal crisis or of crisis in the unit

(g) to contribute to the development of new models for the organisation and leadership of the psychiatric team itself.

These functions are sometimes one-off procedures; but others require an ongoing and regular commitment to a psychiatric unit and its team. In these ways the psychotherapist augments the team's work from a psychodynamic perspective.

Obviously each task is specific, but its fulfilment requires a general appreciation of certain principles which, in total, go beyond an understanding of the psychologies of the individuals involved (both patients and staff) to an understanding of the groups and of the institutions of which they are part.

\section{Guiding principles}

What are the principles which guide the consultant's observations, and offer a framework within which to understand what he perceives? 
(a) An appreciation of the psychodynamics of the institution: Kernberg $(1975,1980)$ integrates a psychoanalytic conceptualisation of the institution with concepts drawn from general systems theory.

A direct (or what Kernberg would call "concentric') application of systems theory would suggest that an institution can be conceptualised as a system of component parts, each in dynamic and hierarchical relationship with the other.

A psychiatric unit can be construed as a system, the components or subsystems of which could be identified at various levels as wards, teams, subgroups within those teams, and the individual patients and staff themselves. The institution of which the unit is a part is the supra-system. A psychoanalytic perspective would perhaps see the individual and his personality as the main system, and the object relationships of his internal world as its sub-systems. To me it matters less where one locates the level of system than that all of its components are seen as having a dynamic relationship to each other.

Kernberg (1975) has drawn attention to the deficiencies of this concentric model, and in particular to the puzzling shifts from moment-to-moment in the apparent hierarchical order and arrangement of the various levels of the system. This, he asserts, is because there is a shifting and dynamic relationship between a number of overlapping or 'nonconcentric' systems, which include the value systems, administrative considerations and political pressures to which the unit is subject. For example, competing non-concentric systems are evident in an in-patient group which is being conducted as an adjunct to other methods of treatment for the patients, but also to train novice therapists, to teach students (who might observe the group through a one-way screen), and for the purposes of research.

A central tenet of systems theory is that processes within any one component of a system will have an inevitable impact upon processes in all the other components. Change in one sub-system will affect the entire system.

One implication of this is that the dynamics of each component have their reflection in the dynamics of all other components. For example, pathological processes in each individual patient on the unit can influence the dynamics of the small group of which he is part; and in turn the ward, the unit, and potentially the institution - unless these dynamics are defused or detoxified en route. Conversely dynamic problems in the organisation of the institution or ward can be magnified downwards to achieve expression in each group on the ward, and in each individual member of it. External and internal (object) relationships are in constant dynamic interaction.

Each level in the hierarchy of the system will display some manifestation of these pervasive dynamic processes. It is for this reason that Levine (1980) suggested that the small in-patient group can serve as a 'biopsy' of the milieu of which it is part.

The consultant, who can place himself at the interface between the many concentric and nonconcentric components, concerns himself with the total system. He operates in turn at each boundary, defining, maintaining and perhaps protecting it. The problematic behaviour of an individual patient, or the demoralisation or recurrent sickness of a staff member, for example, can be understood fully only if seen in this context, as a figure against the ground in a Gestalt.

\section{Example:}

The staff conducting a ward psychotherapy group attributed a sudden increase in absenteeism, conflict and disturbed behaviour among the patients in the group to the arrival on the ward of a new patient, whose behaviour towards the staff was provocative and aggressive. The psychotherapist who supervised their work with the group, and who also conducted a weekly staff sensitivity group on the ward, agreed that the new patient constituted a disruptive influence in the ward. He suggested, however, that the staff and patients might have dealt more constructively with this patient's disruptive influence if it were not for the marked current tensions among the staff which derived from a vicious public confrontation between two senior ward nurses.

At the next meeting of the sensitivity group, these staff members forced a discussion of that event and its significance, leading to some resolution of the tensions within the staff. There was noticeably less "acting out" by the patients subsequently. At its next meeting, the psychotherapy group examined the behaviour of its members. The patients said that they had known of the conflict between the members of staff, and acknowledged the insecurity which this had generated in them. The consultant enabled the staff to recognise that the disturbed behaviour of the patients was less a product of the presence of a difficult patient on the ward but more a reaction to tensions among the staff.

(b) An appreciation of the regressive effects of hospitalisation: It is not possible to understand the experience and behaviour of patients in hospital without an appreciation of the regression that is generated by hospitalisation itself (Kernberg, 1981). This may be the product of at least two processes: (i) The patient's loss of a sense of agency (that is his personal autonomy and effectiveness) which, already threatened by many psychiatric disorders themselves, is undermined further by admission to hospital; and (ii) the regressive pull inevitable in membership of a large group (i.e. the ward and psychiatric unit itself), which threatens and breaks down personal boundaries and defences in a particularly powerful way.

One useful by-product of this process is that the patient's internal dynamics, generally obscured and distorted by his defensive processes, are exposed to view in the regressive setting of the ward both 
through the patient's general behaviour and in his manner of relating to others. These behaviours may well be seen sometimes as problematic unless they are identified as an external manifestation of his problem, i.e. as an externalisation of the disturbance of his inner world.

It is important to recognise that there is a regressive effect for staff too in working within a hospital setting, as in any other institution. The processes described in relation to patients can be identified to some extent in the staff also.

One particular manifestation of these regressive processes is that both patients and staff form intense transferences to the institution in which they find themselves. For some, of course, these transferences will be the source of great security - many patients, like most staff, feel safe in the hospital. For others their transferences will cause them to feel exposed, threatened or even attacked by the institution itself or members of it. The consultant will need to attend to these transferences, which are often unseen until they generate problems in the unit as a whole.

(c) Appreciation of the psychodynamic features of a wide range of personalities and psychopathologies, and of their consequences within the psychiatric setting.

The character structure of certain individuals has an impact on the functioning of the unit as a whole.

Main, in his classic paper 'The Ailment' (1957), drew attention to the splitting and projective processes which are generated within an in-patient unit by certain difficult patients whose psychopathology might now be defined as borderline or narcissistic personality functioning.

Even those of us familiar with such dynamics remain vulnerable to their effects because of the insidious and unconscious manner in which they operate. The consultant, by virtue of being detached and not caught up in direct relationships with individual members of the unit, is better placed to identify and expose these destructive processes.

Obstructive or destructive processes within a hospital unit are generated not only by patients, but by some staff members too. Particularly common is the staff member whose own wellbeing is maintained unconsciously by projective identification with the illness and discomforts of the patients. In its more extreme manifestation, this dynamic can lead the staff member unconsciously to obstruct the recovery of the patient.

Kernberg (1980) has written of other forms of psychopathology which may be found in members of staff, and has pointed particularly to the problems generated by obsessional and narcissistic disorders in those in positions of leadership. Narcissistic individuals, driven by determination and personal ambition, are particularly likely to pursue senior and powerful positions; but their own success is often predicated on their self-seeking and ruthless exploitation of others. In such circumstances, it is highly likely that relationships between members of staff will be fraught and that this will be reflected in their relationships with the patients and in the work of the unit.

(d) No account of the psychodynamic processes operating in the psychiatric in-patient unit would be complete without reference to the social systems operating within such settings as defences against anxiety, processes identified and elucidated by Jaques (1955), Menzies (1959) and Hinshelwood (1987) among others.

For the psychotherapist operating as consultant to an in-patient unit, it is essential to recognise that the various anxieties inherent in working with disturbed and disturbing patients will inevitably provoke defensive processes in the staff. These are likely to be particularly evident in those exposed, day-afterday, to the mental pain, anguish and rage of their patients. Such defensive manoeuvres can become institutionalised in the collective, collusive and unconscious strategies employed by the staff; and sometimes subscribed to by the patients as well. Such defences limit very much the emotional availability of the staff for interactional work with their patients.

Collective defences may be evident especially at times of adversity and demoralisation in the unit. They constitute a formidable challenge to the consultant, and will not go away (any more than will individual defences) simply because challenged. The consultant may need to work steadily with a staff group, over long periods, to expose such processes to collective scrutiny, interpretation and modification.

\section{The active work of consultation}

Awareness of these psychodynamic processes is of little value to the consultant in isolation. He requires also a knowledge of, and sensitivity to, the work of the psychiatric unit. Some understanding of the rationale of the treatments commonly undertaken on the unit is necessary, and clearly the psychotherapist will make little headway in his consultative work if he is antagonistic to the philosophy and work of the unit.

It is also important for the consultant to appreciate something of the culture of each particular unit, and of the day-to-day life, pressures and rewards for the patients and staff in that setting. Indeed it is crucial for the consultant to have an awareness of what Kennedy (1986) has called, albeit in reference to a specialised psychotherapeutic community, the "work of the day" of the patients and of the staff. This is the day-to-day round of problems, worries, thoughts and feelings experienced by each member of 
the unit, patient or staff; daily material which, as yet undigested and unrepressed, can be the focus for the consultant's examination of the life of the unit. In effect it is the unconscious material upon which he focuses his analytic attention.

\section{Example:}

In the example given above, the consultant learnt about the bitter confrontation between two senior nurses through the preoccupations of the patients and staff on the ward, as evidenced by the meetings of the staff sensitivity group and the patients' psychotherapy group. He heard of the patients' collective preoccupation with parental discord and violence, and the anxiety which this seemed to generate in the group during the supervision session. In the sensitivity group later that afternoon, the staff were unusually quiet and apparently evasive. The desultory discussion was focused on the patients and the staff members presen seemed to conspire to avoid questioning or challenging each other's perceptions of the patients or the events in the ward. Sensing the tension in the meeting, the consultant eventually pointed out that they were not talking to each other and that they seemed to be avoiding conflict.

This intervention immediately opened up the subject of the recent confrontation on the ward between the two nurses and exposed the divided loyalties of the nursing staff towards their seniors, only one of whom was present. The conflict was not resolved in that meeting of the sensitivity group; but, as recorded above, the consultant was able to use the next supervision session to attribute the group patients' disturbed behaviour (and their preoccupations with parental strife in the previous week's session) to the conflicts between members of the ward staff.

This brings me lastly to consider what the tasks are for the consultant, and what qualities are required of him to fulfil these tasks. I am suggesting here that there are common psychodynamic tasks which underpin all of his specific functions in the psychiatric unit.

These qualities and tasks include:

(a) a capacity to observe, to listen, and to feel his way into what is going on in the unit

(b) a capacity to tolerate not knowing or understanding what he is perceiving, while holding on to what he does know from prior experience. That is, he needs to be capable of tolerating ignorance without fearing the loss of his mental faculties

(c) this might involve awareness of receiving unconscious projections, and a capacity to contain and process them without immediate action of any kind

(d) such containing necessitates a capacity to think about his experience

(e) the consultant then works towards putting his experience into words, hopefully in a form that will encourage the staff and the patients on the unit to work similarly to make their own sense of their own experience in that setting. His aim is not to tell an audience what is happening, but to help the staff and patients to learn through their own experience.

As in psychotherapy itself, the consultant works towards the uncovering, recognition and modification of processes that hitherto are hidden but obstructive. As suggested above, his aim always is to help the staff to use their selves similarly in their contact with the patients. By this means the self structure and function of each patient may be re-integrated and promoted.

For example the consultant might pick up, at a community meeting or staff group meeting, a considerable degree of unacknowledged tension, discomfort or excitement. He refrains from pointing it out straight away; but, given enough time, he contains the feeling while looking for other information with which to elucidate it. Eventually he may identify the source of the tension in a way that enables him to make an observation to the group which stimulates the curiosity of its members and exploration of their common experience.

I do not think that the consultant's job involves the continuous and relentless exposure of 'truth', in the sense of always challenging the many ways in which, individually and collectively, the members of a psychiatric unit will protect themselves from actually realising their experience. There is a place for challenge, and sometimes this will be necessary to preclude the further development of destructive processes in the unit. At other times though, just as in clinical work with his own patients, the consultant will need to remain quiet or to be actively supportive.

His contribution to the maintenance of morale and therapeutic optimism in the unit will depend on his capacity to know when to be supportive and when to confront.

\section{Comment}

The psychotherapist as consultant to a psychiatric unit operates at the interfaces between individual, group and institution. He functions as a reservoir of psychodynamic knowledge and tolerance, and as a container for intolerable anxiety and ignorance. I have not examined in detail here any of the specific functions undertaken; but I have tried instead to demonstrate something of the framework upon which his various contributions are constructed.

\section{References}

HinsHelwood, R. D. (1987) What Happens in Groups: Psychoanalysis, the Individual and the Community. London: Free Association Books.

JAQUES, E. (1955) Social systems as a defence against persecutory and depressive anxiety. In New Directions in Psychoanalysis (eds M. Klein, P. Heimann \& R. E. Money-Kyrle). London: Tavistock Publications. 
KENNEDY, R. (1986) Work of the day: aspects of work with families at the Cassel Hospital. In The Family as Inpatient (eds R. Kennedy, A. Heymans \& L. Tischler. London: Free Association Books.

KERNBERG, O. (1975) A systems approach to priority setting of interventions in groups. International Journal of Group Psychotherapy, 25, 251-275.

- (1980) Internal World and External Reality. New York: Jason Aronson.

- (1981) Some issues in the theory of hospital treatment. Tidsskr Nor Loegeforen, 101, 837-843.
LEVINE, H. B. (1980) Milieu biopsy: The place of the therapy group on the in-patient ward. International Journal of Group Psychotherapy, 30, 77-93.

MaIN, T. F. (1957) The ailment. British Journal of Medical Psychology, 30, 129-145.

MENZIES, I. E. P. (1959) The functioning of social systems as a defence against anxiety: a report on a study of the nursing service of a general hospital. Human Relations, 13, 95-121. Reprinted in Containing Anxiety in Institutions (I. E. P. Menzies Lyth) (1988). London: Free Association Books.

\title{
Services for pregnant drug users
}

\author{
M. London, Consultant Psychiatrist, Fulbourn Hospital, Cambridge CB1 3DF \\ (correspondence); R. CALDWELL, Senior Biochemist, Poisons Unit, \\ New Cross Hospital, Avonley Road, London SE14; and M. LIPSEDGE, \\ Consultant Psychiatrist, Department of Psychiatry, Guy's Hospital, London SE1
}

Drug and alcohol misuse during pregnancy poses a threat to the health of both the developing foetus and the mother yet this complex clinical problem often falls between different stools within the health services. A mother would first have to recognise herself as a drug or alcohol misuser needing help before she came within the ambit of the addiction services. On the other hand, the obstetric agencies, even when they identify a drug problem, usually do not regard themselves as having a role. General practitioners are most likely to have an overall view and therefore to be in the best position to manage the problem. However, many misusers do not register with GPs and, despite calls to the contrary, GPs have not become more widely involved in the management of addiction.

\section{The Project}

The Pregnant Misuser Project was started in Guy's Hospital in December 1987 with the aim of ascertaining the size of the problem and providing a service where one was lacking. Local services for misusers consist of a non-statutory shop-front agency and a drug dependency unit. In order to estimate the size of the problem, random urine surveys of pregnant mothers were carried out in the antenatal clinic. A midwife explained the purpose of the survey to mothers booking into the clinic for the first time. They were told that their urine would be tested for alcohol, tranquillisers or illicit substances but that whatever the result their antenatal care would continue regardless. The urine samples were screened for opiates and barbiturates by Thin Layer Chromatography (TLC) and for benzodiazepines, cannabis, cocaine and amphetamines using immuno assays. All mothers were later informed of the results of their tests. Such a survey obviously raised ethical issues but most of the staff felt that these issues were adequately addressed by conducting the survey on a voluntary, open basis.

Once a week one of the authors (MLn) was available to see individual mothers in the antenatal clinic. This would be arranged by the midwives. They would 